\title{
Predicting factors for abnormal brain computed tomography in children with minor head trauma
}

Taraneh Naghibi ${ }^{1}$, Mina Rostami ${ }^{2}$, Behrad Jamali ${ }^{3}$, Zhaleh Karimimoghaddam ${ }^{4}$, Alireza Zeraatchi ${ }^{3^{*}}$ and Asghar Jafari Rouhi ${ }^{3}$

\begin{abstract}
Background: Deciding whether a cranial Computed Tomography (CT) scan in a patient with minor head trauma $(\mathrm{MHT})$ is necessary or not has always been challenging. Diagnosing Traumatic Brain Injury (TBI) is a fundamental part of MHT managing especially in children who are more vulnerable in terms of brain CT radiation consequences and TBI. Defining some indications to timely and efficiently predict the likelihood of TBI is necessary. Thus, we aimed to determine the impact of clinical findings to predict the need for brain $\mathrm{CT}$ in children with MHT.

Methods: In a prospective cohort study, 200 children (2 to 14 years) with MHT were included from 2019 to 2020. The data of MHT-related clinical findings were gathered. The primary and secondary outcomes were defined as a positive brain $\mathrm{CT}$ and any TBI requiring neurosurgery intervention, respectively. In statistical analysis, we performed Binary Logistic regression analysis, Fisher's exact test and independent samples t-test using SPSS V.26.

Results: The mean age of participants was $6.5 \pm 3.06$ years. Ninety patients underwent brain CT. The most common clinical finding and injury mechanism were headache and falling from height, respectively. The results of brain CTs were positive in seven patients (3.5\%). We identified three predicting factors for an abnormal brain CT including headache, decreased level of consciousness, and vomiting.
\end{abstract}

Conclusion: We showed that repetitive vomiting $(\geq 2)$, headache, and decreased level of consciousness are predicting factors for an abnormal brain CT in children with MHT.

Keywords: Minor head trauma, Children, Traumatic brain injury, Brain computed tomography scan

\footnotetext{
* Correspondence: zeraatchi.zums@gmail.com

${ }^{3}$ Department of Emergency Medicine, School of Medicine, Valiasr-e-Asr

Hospital, Ayatollah Mousavi Hospital, Zanjan University of Medical Sciences,

Zanjan, Iran

Full list of author information is available at the end of the article
}

C C The Author(s). 2021 Open Access This article is licensed under a Creative Commons Attribution 4.0 International License, which permits use, sharing, adaptation, distribution and reproduction in any medium or format, as long as you give appropriate credit to the original author(s) and the source, provide a link to the Creative Commons licence, and indicate if changes were made. The images or other third party material in this article are included in the article's Creative Commons licence, unless indicated otherwise in a credit line to the material. If material is not included in the article's Creative Commons licence and your intended use is not permitted by statutory regulation or exceeds the permitted use, you will need to obtain permission directly from the copyright holder. To view a copy of this licence, visit http://creativecommons.org/licenses/by/4.0/. The Creative Commons Public Domain Dedication waiver (http://creativecommons.org/publicdomain/zero/1.0/) applies to the data made available in this article, unless otherwise stated in a credit line to the data. 


\section{Key messages}

1. The prevalence of Traumatic Brain Injury (TBI) in children with minor head trauma is considerably low.

2. Repetitive vomiting, headache, and decreased level of consciousness may be predictors of an abnormal brain CT in children with minor head trauma.

3. Falling from height is the most common mechanism of head trauma among children.

\section{Background}

Head trauma, as one of the most common causes of emergency department (ED) visits, can have serious and fatal consequences including traumatic brain injury (TBI) [1]. Although not all types of head trauma lead to significant consequences, proper management and early detection of TBI is of paramount importance [2]. Annually, a significant number of TBI cases are diagnosed worldwide and notably a meaningful portion of which occur in low and middle-income countries (LMIC) countries [3]. Importantly, a substantial part of head trauma statistics is related to pediatric population which is estimated to have an incidence of $180-300$ per 100,000 [4]. Among pediatric population, most cases of head trauma are minor (Glasgow Coma Scale (GCS) $\geq 14$ ) and intracranial injuries are uncommon, so that on average $5 \%$ of minor head traumas (MHT) in children lead to TBI and of this less than $1 \%$ requires neurosurgical intervention [5]. Patients with MHT have a GSC of 14 to 15 , and may initially experience transient loss of consciousness (LOC) or amnesia, but present without focal neurological defects on admission [4]. Cranial CT scan is the reference standard of diagnosing TBI. Deciding in which patients with MHT performing a brain CT is needed has always been challenging and appraisal of its necessity in the management of pediatric head trauma has been even more important [6].

Brain CT overuse imposes high costs on the healthcare system of countries especially in LMIC [3, 7]. Unfortunately, in such countries Access to CT is difficult and sometimes only available in capital cities. As a result, in such cases, patients are referred to big hospitals. Thus, requesting unnecessary brain CTs can lead to a remarkable burden on the patients and the healthcare systems. In addition, exposure to brain $\mathrm{CT}$ radiation might be associated with an increased susceptibility to leukemia and brain tumors in children [8].

There are signs and symptoms that increase likelihood of occurring TBI in children with head trauma (i.e. posttraumatic seizures, headache, amnesia, scalp hematoma, skull fracture, vomiting after head trauma and loss of consciousness) [1,9]. Given that the most cases of head trauma are minor head trauma (89\% of all cases) [1], and the fact that more than $90 \%$ of CT scans do not indicate brain injury [10], the need to use clinical findings to recognize which patients are more prone to TBI is crucial [11]. Moreover, it is important not to limit clinical judgment to head trauma decision-making rules alone, as their sensitivities and specificities have been shown to be low in some studies [12,13]. Therefore, appraising the presence of TBI in children with MHT using the clinical findings acquired from history taking and physical examination is of great importance in order to avoid unnecessary brain CTs and predict TBIs more efficiently.

The objective of the current study was to identify the accuracy of clinical findings to predict the need for brain $\mathrm{CT}$ in children with MHT.

\section{Methods and materials}

In a prospective study, we included 200 children with minor head trauma aged 2 to 14 years who had been referred to the ED of Ayatollah Mousavi Hospital in Zanjan, Iran from May 2019 to March 2020. The trauma ED of Ayatollah Mousavi Hospital is the reference hospital in the whole province which patients with head trauma and high suspicion of TBI are also referred to this ED from other cities of Zanjan that do not have brain CT facilities.

\section{Study subjects}

Inclusion criteria were considered children aged 2 to 14 years, blunt head trauma within the first $24 \mathrm{~h}$ before the ED visit and GCS score of $\geq 14$. We excluded all patients with a history of anticoagulant therapy, GCS $\leq 13$, underlying cerebral diseases (i.e. brain tumors, ischemic or hemorrhagic lesions), penetrating head trauma, ventricular shunts and presenting to the ED after $24 \mathrm{~h}$ of head trauma.

Study design and protocol was approved by the Ethics Committee of Zanjan University of Medical Sciences [IR.ZUMS.REC.1398.024].

\section{Data collection and measurements}

The data obtained from the history taking, physical examination and the results of brain CTs or follow ups were recorded in the forms designed for this purpose by emergency medicine physicians or residents. In fact, the study population was categorized into three groups $(6 \mathrm{~h}$ follow up, brain CT, and discharge) according to ED physician's decision on the basis of clinical signs and symptoms (Fig. 1). In other words, patients with high suspicion of TBI were referred to undergo a brain CT, patients with moderate suspicion of TBI were monitored in the ED for $6 \mathrm{~h}$, and in case of any TBI-related signs and symptoms were referred to receive a brain $\mathrm{CT}$. The rest of the patients who had very low clinical suspicion 


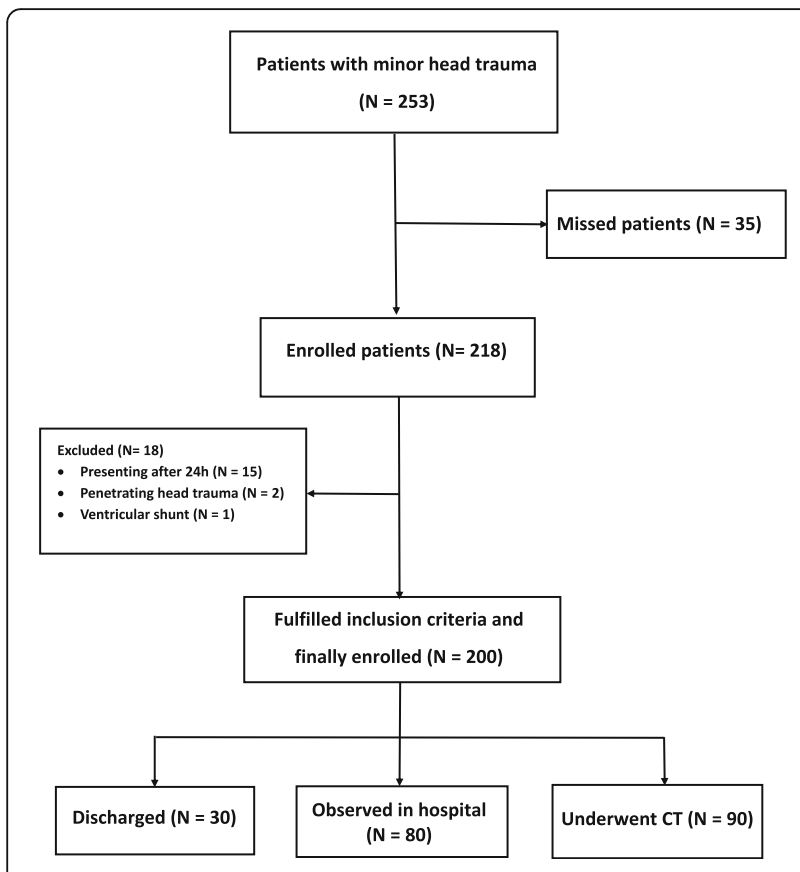

Fig. 1 Study flow diagram

of TBI were discharged after explaining the TBI precautions (i.e. lowered level or loss of consciousness (LOC), persistent vomiting of at least two times, not acting normally to parents, cerebrospinal fluid rhinorrhea, and posttraumatic seizure) $[1,14]$ to their parents and they were asked to return promptly to the ED if any signs or symptoms relevant to TBI occurred. All CT images were interpreted by an experienced board certified radiologist.

Patients who did not undergo CT were followed up for one week after discharge and at the end of the seventh day were interviewed by an experienced nurse by phone calling to assess whether or not any TBI-related symptoms occurred, if there were any symptoms they were asked to undergo a cranial CT.

The scores of Pediatric Glasgow Coma Scale (PGCS) was used to assess the level of consciousness in children with MHT. PGCS evaluates children under 23 months, 2 to 5 years and over 5 years separately in three parts of verbal response, eye opening, and motor response [14].

Clinical findings of patients included repetitive vomiting $(\geq 2)$, headache, decreased level of consciousness, posttraumatic seizure, posttraumatic amnesia, signs of skull base fracture (Battle sign, raccoon eyes, hemotympanum, and cerebrospinal fluid otorrhea or rhinorrhea), palpable skull fracture, scalp hematoma, acting abnormally to parents, and any bruising, abrasions or lacerations on face or scalp.

Additionally, we studied injury mechanisms included, fall from height, fall from stairs, ground level falls, hitting injury and any accident (pedestrian hit by car, bicycle-related accidents, motor vehicle accident, car rollover, and unrestrained).

\section{Outcome measures}

Primary outcome was considered as an abnormal brain CT (i.e. pneumocephalus, cerebral contusion, subdural, epidural, ventricular or parenchymal hematoma, herniation, and skull fracture (depressed or linear)).

Secondary outcomes were any abnormality in brain $\mathrm{CT}$ requiring neurosurgery (i.e. elevation of skull fracture, craniotomy, intracranial pressure monitoring, and external ventricular drainage).

\section{Statistical analysis}

In descriptive statistics, we reported continuous data as mean \pm standard deviation (SD) or median with interquartile ranges (IQR), as applicable. Fisher's exact test was used to evaluate the relationship between outcomes and predicting factors for categorical data. Independent samples t-test was used to compare the mean of continuous variables between two groups. We performed a binary Logistic regression analysis to determine which predicting factors can be considered as a risk indicator for a positive CT. Significance level was considered < 0.05. We performed all statistical analysis using SPSS V.26.

\section{Results}

We included 200 children (134 males and 66 females) with MHT. The mean age of participants was $6.5 \pm 3.06$ years. Ninety patients received brain CT and none of the participants in the two other groups required a CT scan during the follow-up period.

Of participants, 76 (38\%) showed no clinical findings. Headache $(34 \%)$ was the most common clinical finding. Additionally, the most frequent injury mechanism was fall from height (37.5\%) (Table 1).

We found 7 patients (3.5\%) with positive brain CT including 1 patient with pneumocephalus, 2 with subdural hematoma, 1 with cerebral contusion, and 3 with linear skull fracture. However, none of the patients underwent neurosurgery (secondary outcome), 10 patients underwent neurosurgery counseling and were admitted to the neurosurgery ward to be monitored.

In examining the relationship between the clinical findings and abnormal brain CTs, there was a statistically significant relationship between headache, repetitive vomiting and decreased level of consciousness with abnormal brain CT (Table. 2).

In addition, no statistically significant relationship was found between injury mechanisms and abnormal brain CT (Table 3). 
Table 1 Basic characteristics of the participants

\begin{tabular}{ll}
\hline Variable & N (\%) or mean \pm SD \\
\hline Gender, male & $134(67)$ \\
Age, year & $6.5 \pm 3.06$ \\
Clinical findings & \\
Repetitive vomiting & $27(13.5)$ \\
Headache & $66(33.0)$ \\
LOC & $33(16.5)$ \\
Posttraumatic amnesia & $16(8.0)$ \\
Scalp hematoma & $17(8.5)$ \\
Wound on face or scalp & $33(16.5)$ \\
Acting abnormally & $6(3.0)$ \\
Palpable skull fracture & $0(0)$ \\
Signs of skull base fracture & $0(0)$ \\
Posttraumatic seizure & $0(0)$ \\
Trauma mechanism & \\
Fall from height & $75(37.5)$ \\
Fall from stairs & $34(17.0)$ \\
Ground level fall & $44(22.0)$ \\
Bicycle-related accidents & $16(8.0)$ \\
Hitting injury & $8(4.0)$ \\
Motor vehicle accident & $7(3.5)$ \\
Car rollover & $6(3.0)$ \\
Unrestrained & $10(5.0)$ \\
Pedestrian hit by car & $0(0)$ \\
\hline &
\end{tabular}

LOC Loss of Consciousness

In addition, no statistically significant relationship was found between injury mechanisms and abnormal brain CT (Table 3).

The results of independent samples t-test also revealed no significant relationship between age and an abnormal brain CT (t $(198)=-1.36, P=0.17)$.

In order to determine the effect of independent variables to predict a positive cranial CT finding, we performed a binary logistic regression. Taking into account the fact that the number of predictors in our study were more than the number of events, we entered variables into the analysis using a forward selection method. The predicted variable was the presence or absence of a positive CT scan (7 events). Predictors were considered gender, age, repetitive vomiting, headache, LOC, posttraumatic amnesia, scalp hematoma, wound on face or scalp, acting abnormally, fall from height, fall from stairs, ground level fall, bicycle-related accidents, hitting injury, motor vehicle accident, Car rollover, unrestrained (Table 4).

Finally, three predicting factors for abnormal brain CT including headache $(p=0.035)$, decreased level of
Table 2 Relationship between clinical findings and abnormal brain $\mathrm{CT}$

\begin{tabular}{|c|c|c|c|c|}
\hline \multirow[t]{2}{*}{ Variables } & \multicolumn{2}{|c|}{$\begin{array}{l}\text { Abnormal CT } \\
\mathrm{N}(\%)\end{array}$} & \multirow[t]{2}{*}{$P$-value ${ }^{a}$} & \multirow[t]{2}{*}{ LR } \\
\hline & Yes & No & & \\
\hline \multicolumn{5}{|l|}{ Male } \\
\hline Yes & $4(3.0)$ & $130(97.0)$ & 0.68 & 0.3 \\
\hline No & $3(4.5)$ & $63(95.5)$ & & \\
\hline \multicolumn{5}{|l|}{ Headache } \\
\hline Yes & $6(9.1)$ & $60(90.9)$ & 0.006 & 8.68 \\
\hline No & $1(0.7)$ & $133(99.3)$ & & \\
\hline \multicolumn{5}{|l|}{ Vomiting } \\
\hline Yes & $4(14.8)$ & $23(85.2)$ & 0.007 & 7.75 \\
\hline No & $3(1.7)$ & $170(98.3)$ & & \\
\hline \multicolumn{5}{|l|}{ LOC } \\
\hline Yes & $5(15.2)$ & $28(84.8)$ & 0.002 & 10.93 \\
\hline No & $2(1.2)$ & $165(98.8)$ & & \\
\hline \multicolumn{5}{|c|}{ Posttraumatic amnesia } \\
\hline Yes & $0(0)$ & $16(100)$ & 1.00 & 1.18 \\
\hline No & $7(3.8)$ & $177(96.2)$ & & \\
\hline \multicolumn{5}{|c|}{ Scalp hematoma } \\
\hline Yes & $0(0)$ & 17 (100\%) & 1.00 & 1.26 \\
\hline No & $7(3.8)$ & $176(96.2)$ & & \\
\hline \multicolumn{5}{|c|}{ Wound on face or scalp } \\
\hline Yes & $1(3.0)$ & $32(97.0)$ & 1.00 & 0.02 \\
\hline No & $6(3.6)$ & $161(96.4)$ & & \\
\hline \multicolumn{5}{|c|}{ Acting abnormally } \\
\hline Yes & $1(16.7)$ & $5(83.3)$ & 0.19 & 1.75 \\
\hline No & $6(3.1)$ & $188(96.9)$ & & \\
\hline
\end{tabular}

${ }^{\mathrm{a}} P$-values obtained from Fisher's exact test, $P<0.05$

LR Likelihood Ratio, CT Computed Tomography, LOC Loss of Consciousness

consciousness $(p=0.002)$, and vomiting $(p=0.017)$ were recognized.

Indeed, these results imply that the presence of headache, vomiting and decreased level of consciousness in children with MHT might increase the odds of finding a positive cranial CT by more than 12 times, 12 times and 26 times, respectively.

For further analysis, we regarded the presence of clinical findings as well as the rate of different combinations of the three predicting factors we obtained (Table 5).

The results showed that 76 patients $(37.8 \%)$ did not report any clinical findings. Besides, the presence of clinical findings was significantly associated with having an abnormal CT finding $(P=0.046)$, namely all 7 cases of abnormal cranial CT were reported in the group of patients with clinical findings.

In terms of patients reporting clinical findings (124 patients) there were 24 patients $(11.9 \%)$ without 3 
Table 3 Relationship between injury mechanisms and abnormal brain $\mathrm{CT}$

\begin{tabular}{|c|c|c|c|c|}
\hline \multirow[t]{2}{*}{ Variables } & \multicolumn{2}{|c|}{$\begin{array}{l}\text { Abnormal CT } \\
\mathrm{N}(\%)\end{array}$} & \multirow[t]{2}{*}{$P$-value ${ }^{a}$} & \multirow[t]{2}{*}{ LR } \\
\hline & Yes & No & & \\
\hline \multicolumn{5}{|c|}{ Fall from height } \\
\hline Yes & $4(5.3)$ & $71(94.7)$ & 0.42 & 1.14 \\
\hline No & $3(2.4)$ & $122(97.6)$ & & \\
\hline \multicolumn{5}{|c|}{ Fall from stairs } \\
\hline Yes & $0(0)$ & $34(100)$ & 0.6 & 2.66 \\
\hline No & $7(4.2)$ & $159(95.8)$ & & \\
\hline \multicolumn{5}{|c|}{ Ground level fall } \\
\hline Yes & $0(0)$ & $44(100)$ & 0.35 & 3.54 \\
\hline No & $7(4.5)$ & $149(95.5)$ & & \\
\hline \multicolumn{5}{|c|}{ Bicycle-related accidents } \\
\hline Yes & $0(0)$ & $16(100)$ & 1.00 & 1.18 \\
\hline No & $7(3.8)$ & $177(96.2)$ & & \\
\hline \multicolumn{5}{|c|}{ Hitting injury } \\
\hline Yes & $0(0)$ & $8(100)$ & 1.00 & 0.58 \\
\hline No & $7(3.6)$ & $185(96.4)$ & & \\
\hline \multicolumn{5}{|c|}{ Motor vehicle accident } \\
\hline Yes & $1(14.3)$ & $6(85.7)$ & 0.22 & 1.48 \\
\hline No & $6(3.1)$ & $187(96.9)$ & & \\
\hline \multicolumn{5}{|l|}{ Car rollover } \\
\hline Yes & $1(16.7)$ & $5(83.3 \%)$ & 0.19 & 1.75 \\
\hline No & $6(3.1)$ & 188 (96.9\%) & & \\
\hline \multicolumn{5}{|c|}{ Unrestrained } \\
\hline Yes & $1(10.0)$ & $9(90.0)$ & 0.3 & 0.91 \\
\hline No & $6(3.2)$ & $184(96.8)$ & & \\
\hline
\end{tabular}

${ }^{a} P$-values obtained from Fisher's exact test, $P<0.05$

LR Likelihood Ratio, CT Computed Tomography

predicting factors. No patient with a positive CT was found among patients with none of the predictors so that presence of predicting factors was significantly associated with finding an abnormal $\mathrm{CT}$ in patients $(P=0.014)$.

Experiencing only one of the predictors (LOC or vomiting or headache) was not significantly associated with showing a positive CT (All, $p>0.05$ ).
Considering the combinations of two predictors, all three showed a statistically significant association with having an abnormal CT (Table 5). According to the odds ratios, headache + LOC showed the greatest one equal to 28.20 (95\% CI, 4.94-160.75), indicating that odds of finding an abnormal CT while the patient presents with headache + LOC seems to be nearly 28 times more than finding an abnormal CT when the patient does not present with headache + LOC. Similarly, in terms of vomiting + headache, with odds ratio equal to 9.25 (95\% CI, 1.55-55.18), the odds of having an abnormal CT in patients with vomiting + headache might be approximately 9 times more than patients without this combination. Considering vomiting + LOC, the odds ratio less than 1, implies 0.03 odds of having an abnormal CT in patients with vomiting + LOC vs. patients without that combination. However, experiencing vomiting + headache + LOC was not statistically significantly associated with having an abnormal CT $(P=0.102)$, the odds ratio of 15.91 (95\% CI, 1.26-200.66) signifies that the odds of finding an abnormal CT is nearly 15 times more in patients with this combination than those without it.

\section{Discussion}

Minor head trauma is a common problem in children. In some cases, blunt MHT may be associated with TBI. Because the management and requesting brain $\mathrm{CT}$ in children with MHT is controversial, physicians usually tend to order a brain CT for most children with MHT, while TBI is seen only in a few cases. In the current study only $3.5 \%$ of children with MHT had positive brain CTs, similar to several other studies that have reported TBI in a very few cases with MHT $[2,4,5]$.

Although the story is somewhat different in developing countries, Norlund et al showed that CT was a more cost-effective strategy than monitoring MHT patients at ED [15]. In addition, Geijerstam et al reported that CT was an attainable strategy in MHT patients and resulted in similar outcomes in comparison with observation [16]. Nevertheless, to assess the necessity of ordering brain $\mathrm{CT}$ in children with MHT is not just about the costs to healthcare system or the availability of CT, it is also important not to expose children to radiation as it can increase

Table 4 Predicting factors for an abnormal brain $C T^{a}$

\begin{tabular}{lllll}
\hline Predictors $^{\mathbf{b}}$ & Coefficient & Standard error & OR (95\% Cl) & \multicolumn{1}{c}{-value } \\
\hline LOC & 3.27 & 1.06 & $26.53(3.28,214.34)$ & 0.002 \\
Vomiting & 2.50 & 1.05 & $12.29(1.57,96.26)$ & 0.017 \\
Headache & 2.49 & 1.18 & $12.10(1.19,122.47)$ & 0.035 \\
Constant & -6.95 & 1.44 & 0.001 & 0.000 \\
\hline
\end{tabular}

apredicting factors were defined using binary Logistic Regression with a forward selection method

${ }^{b}$ Only variables with a $p<0.05$ were included in the model

OR Odds Ratio, CI Confidence Interval, CT Computed Tomography, LOC Loss of Consciousness 
Table 5 Positive CT findings by number of three predicting factors

\begin{tabular}{|c|c|c|c|c|c|}
\hline \multirow{2}{*}{$\begin{array}{l}\text { Predictors } \\
\text { Number of clinical findings }\end{array}$} & \multicolumn{2}{|c|}{$\begin{array}{l}\text { Abnormal CT } \\
\mathrm{N}(\%)\end{array}$} & \multirow[t]{2}{*}{$\begin{array}{l}\text { Total } \\
\text { N (\%) }\end{array}$} & \multirow[t]{2}{*}{ OR $(95 \% \mathrm{Cl})$} & \multirow[t]{2}{*}{$P$-value ${ }^{a}$} \\
\hline & Yes & No & & & \\
\hline 0 & $0(0)$ & $76(100)$ & $76(100)$ & $0.60(0.54,0.67)$ & 0.046 \\
\hline$\geq 1$ & $7(5.6)$ & $117(94.4)$ & $124(100)$ & & \\
\hline \multicolumn{6}{|l|}{ Presence of predictors } \\
\hline \multicolumn{6}{|l|}{ Presence of predictors } \\
\hline No & $0(0)$ & $100(100)$ & $100(100)$ & $1.07(1.01,1.13)$ & 0.014 \\
\hline Yes & $7(7)$ & $93(93)$ & $100(100)$ & & \\
\hline \multicolumn{6}{|l|}{ Presence of 1 predictor } \\
\hline \multicolumn{6}{|l|}{ LOC } \\
\hline Yes & $0(0)$ & $20(100)$ & $20(100)$ & $0.96(0.93,0.99)$ & 1.000 \\
\hline No & $7(3.9)$ & $173(96.1)$ & $180(100)$ & & \\
\hline \multicolumn{6}{|l|}{ Vomiting } \\
\hline Yes & $0(0)$ & $13(100)$ & $13(100)$ & $0.96(0.93,0.99)$ & 1.000 \\
\hline No & $7(3.7)$ & $180(96.3)$ & $187(100)$ & & \\
\hline \multicolumn{6}{|l|}{ Headache } \\
\hline Yes & $0(0)$ & $45(100)$ & $45(100)$ & $0.95(0.92,0.98)$ & 0.353 \\
\hline No & $7(4.5)$ & $148(95.5)$ & $155(100)$ & & \\
\hline \multicolumn{6}{|l|}{ Presence of 2 predictors } \\
\hline \multicolumn{6}{|l|}{ Vomiting + Headache } \\
\hline Yes & $2(20.0)$ & $8(80.0)$ & $10(100)$ & $9.25(1.55,55.18)$ & 0.041 \\
\hline No & $5(2.6)$ & $185(97.4)$ & $190(100)$ & & \\
\hline \multicolumn{6}{|l|}{ Vomiting + LOC } \\
\hline Yes & $1(100)$ & $0(0)$ & $1(100)$ & $0.03(0.01,0.06)$ & 0.035 \\
\hline No & $6(3)$ & $193(97)$ & $199(100)$ & & \\
\hline \multicolumn{6}{|l|}{ Headache + LOC } \\
\hline Yes & $3(37.5)$ & $5(62.5)$ & $8(100)$ & $28.20(4.94,160.75)$ & 0.001 \\
\hline No & $4(2.1)$ & $188(97.9)$ & $192(100)$ & & \\
\hline \multicolumn{6}{|l|}{ Presence of 3 predictors } \\
\hline \multicolumn{6}{|l|}{ Vomiting + Headache + LOC } \\
\hline Yes & $1(33.3)$ & $2(66.7)$ & $3(100)$ & $15.91(1.26,200.66)$ & 0.102 \\
\hline No & $6(3.0)$ & $191(97.0)$ & $197(100)$ & & \\
\hline
\end{tabular}

${ }^{\mathrm{a} P} P$-values obtained from Fisher's exact test, $P<0.05$

OR Odds Ratio, CI Confidence Interval, CT Computed Tomography, LOC Loss of Consciousness

the risk of malignancy in them. It should be noted that the use of CT in children is more than adults and is on the rise. This can have various reasons, such as the physician's fear of missing a TBI in children with MHT or the difficulties of monitoring children at ED $[17,18]$.

We observed a statistically significant association between repetitive vomiting, decreased level of consciousness, and headache with abnormal brain CT whereas there was not any significant relationship between mechanisms of injury and a positive brain CT. It implies that repetitive vomiting, decreased consciousness and headache might be three predicting factors for an abnormal brain CT in children presenting with MHT.

Emerging evidence has confirmed the importance of vomiting, especially repetitive vomiting $(2 \leq)$, as a risk indicator for TBI [1]. Vaniyapong et al in their study have demonstrated repetitive vomiting and headache as clinical predictors for TBI [19].

However, in many pediatric head trauma guidelines repetitive vomiting has been indicated as a predicting factor for TBI, there is ample evidence that no association exists between TBI and vomiting. Interestingly, it has been concluded that vomiting in children after head 
trauma may be more closely related to individual or familial predisposition than to the presence of TBI [20]. Moreover, Studies have shown that there is a significant difference between isolated vomiting and non-isolated vomiting as a factor in predicting TBI likelihood, so that isolated vomiting is not significantly associated with TBI [21]. Similar to the present study that none of the $7 \mathrm{pa}-$ tients with abnormal CT had isolated symptoms.

Headache and decreased level of consciousness are also clinical findings that may help predict TBI in patients with MHT. Nonetheless, this is also controversial and some evidence has revealed conflicting results in terms of headache and decreased consciousness as risk indicators for MHT [1]. Sharif-Alhoseini et al in a study of risk indicators for abnormal brain CT have determined headache and loss of consciousness as clinical findings to predict a positive CT in patients with MHT [22]. In addition, there are other studies that have shown headache, loss of consciousness, and vomiting moderately increase the probability of an abnormal CT in children with MHT [23].

Another finding of the present study is the highest frequency of falling from height among the mechanisms of trauma. It has been demonstrated that in the age group of $0-14$ years, the main mechanism of trauma is falling from height [14].

Although according to our findings there was no significant relationship between gender and an abnormal $\mathrm{CT}$, various studies indicate that there is a significant difference in the likelihood of TBI between boys and girls, so that boys are about 2 times more likely to develop TBI after a head trauma than girls [14, 24].

\section{Limitations}

The main limitation of the present study is the low sample size and therefore the low number of positive CT findings that can limit the power of the current analysis. However, over a one-year period, the authors included all eligible minor head trauma cases who referred to the only trauma center of the Zanjan province.

\section{Conclusion}

In summary, we observed abnormal brain CT in only $3.5 \%$ of children with MHT. Repetitive vomiting, decreased level of consciousness, and headache were clinical findings that we showed to be significantly associated with a positive CT. Thus, we found 3 predicting factors for abnormal brain $\mathrm{CT}$ in children with MHT.

\section{Abbreviations}

CT: Computed Tomography; MHT: Minor Head Trauma; TBI: Traumatic Brain Injury; ED: Emergency Department: LMIC: Low and Middle-Income Countries; GCS: Glasgow Coma Scale; LOC: Loss Of Consciousness; PGCS: Pediatric
Glasgow Coma Scale; SD: Standard Deviation; IQR: Inter Quartile Range; LR: Likelihood Ratio

\section{Acknowledgements}

None.

\section{Authors' contributions}

$A Z, M R, B J, Z H K, A J R$, and TN designed the study. AZ and AJR supervised the study. MR and BJ conducted the statistical analysis. BJ provided the data and performed data analyses and quality control. MR and BJ drafted the manuscript. All authors contributed substantially to its revision. AZ takes responsibility for the paper as a whole. All authors read and approved the final manuscript.

\section{Funding}

This study was performed without funding.

\section{Availability of data and materials}

The datasets used and analyzed during the current study are available from the corresponding author on reasonable request.

\section{Declarations}

Ethics approval and consent to participate

Study design and protocol was approved by the Ethics Committee of Zanjan University of Medical Sciences [IR.ZUMS.REC.1398.024].

Consent for publication

Not applicable.

\section{Competing interests}

Authors declare no conflicts of interest.

\section{Author details}

${ }^{1}$ Department of Anesthesiology and Critical Care Medicine, School of Medicine, Ayatollah Mousavi Hospital, Zanjan University of Medical Sciences, Zanjan, Iran. ${ }^{2}$ Social Determinants of Health Research Center, Zanjan University of Medical Sciences, Zanjan, Iran. ${ }^{3}$ Department of Emergency Medicine, School of Medicine, Valiasr-e-Asr Hospital, Ayatollah Mousavi Hospital, Zanjan University of Medical Sciences, Zanjan, Iran. ${ }^{4}$ Department of Radiation Oncology, School of Medicine, Valiasr-e-Asr Hospital, Zanjan

University of Medical Sciences, Zanjan, Iran.

Received: 9 September 2021 Accepted: 10 November 2021

Published online: 19 November 2021

References

1. Easter JS, Haukoos JS, Meehan WP, Novack V, Edlow JA. Will neuroimaging reveal a severe intracranial injury in this adult with minor head trauma?: the rational clinical examination systematic review. Jama. 2015;314(24):2672-81. https://doi.org/10.1001/jama.2015.16316.

2. Lorton F, Poullaouec C, Legallais $E$, et al. Validation of the PECARN clinical decision rule for children with minor head trauma: a French multicenter prospective study. Scand J Trauma Resusc Emerg Med. 2016;24:98. https:// doi.org/10.1186/s13049-016-0287-3.

3. Subaiya S, Roberts I, Komolafe E, Perel P. Predicting intracranial hemorrhage after traumatic brain injury in low and middle-income countries: a prognostic model based on a large, multi-center, international cohort. BMC Emerg Med. 2012;12:17. https://doi.org/10.1186/1471-227x-12-17.

4. Astrand R, Rosenlund C, Undén J. Scandinavian guidelines for initial management of minor and moderate head trauma in children. BMC Med. 2016:14:33. https://doi.org/10.1186/s12916-016-0574-x.

5. Easter JS, Bakes K, Dhaliwal J, Miller M, Caruso E, Haukoos JS. Comparison of PECARN, CATCH, and CHALICE rules for children with minor head injury: a prospective cohort study. Ann Emerg Med. 2014;64(2):145-52. https://doi. org/10.1016/j.annemergmed.2014.01.030.

6. Shetty VS, Reis MN, Aulino JM, Berger KL, Broder J, Choudhri AF, et al. ACR appropriateness criteria head Trauma. J Am Coll Radiol. Jun 2016;13(6):66879. https://doi.org/10.1016/j.jacr.2016.02.023. 
7. Melnick ER, Szlezak CM, Bentley SK, Dziura JD, Kotlyar S, Post LA. CT overuse for mild traumatic brain injury. Jt Comm J Qual Patient Saf. 2012;38(11):4839. https://doi.org/10.1016/s1553-7250(12)38064-1.

8. Pearce MS, Salotti JA, Little MP, et al. Radiation exposure from CT scans in childhood and subsequent risk of leukaemia and brain tumours: a retrospective cohort study. Lancet. 2012;380(9840):499-505. https://doi.org/1 0.1016/s0140-6736(12)60815-0.

9. Lumba-Brown A, Yeates KO, Sarmiento K, Breiding MJ, Haegerich TM, Gioia GA, et al. Diagnosis and Management of Mild Traumatic Brain Injury in children: a systematic review. JAMA Pediatr. 2018;172(11):e182847. https:// doi.org/10.1001/jamapediatrics.2018.2847.

10. Stiell IG, Clement CM, Grimshaw JM, Brison RJ, Rowe BH, Lee JS, et al. A prospective cluster-randomized trial to implement the Canadian CT head rule in emergency departments. CMAJ. 2010;182(14):1527-32. https://doi. org/10.1503/cmaj.091974

11. Mohammaddoust M, Chokan NM, MoshirianFarahi S, Tavakolian A, Foroughian M. ACEP's Recommendations for Brain Computed Tomography Scan in Adult Minor Head Trauma Patients; a Diagnostic Accuracy Study. Arch Acad Emerg Med. 2020;8(1):e86.

12. Bozan Ö, Aksel G, Kahraman HA, Giritli Ö, Eroğlu SE. Comparison of PECARN and CATCH clinical decision rules in children with minor blunt head trauma. Eur J Trauma Emerg Surg. Oct 2019;45(5):849-55. https://doi.org/10.1007/ s00068-017-0865-8.

13. Gizli G, Durak VA, Koksal O. The comparison of PECARN, CATCH, AND CHALICE criteria in children under the age of 18 years with minor head trauma in emergency department. Hong Kong J Emerg Med. 2020: 102490792093051. https://doi.org/10.1177/1024907920930510.

14. Derakhshanfar H, Pourbakhtyaran E, Rahimi S, Sayyah S, Soltantooyeh Z, Karbasian F. Clinical guidelines for traumatic brain injuries in children and boys. Eur J Transl Myol. 2020;30(1):8613-170. https://doi.org/10.4081/ejtm.2 019.8613.

15. Norlund A, Marké LA, af Geijerstam JL, Oredsson S, Britton M. Immediate computed tomography or admission for observation after mild head injury; cost comparison in randomised controlled trial. Bmj. 2006;333(7566):469. https://doi.org/10.1136/bmj.38918.659120.4F.

16. af Geijerstam JL, Oredsson S, Britton M. Medical outcome after immediate computed tomography or admission for observation in patients with mild head injury: randomised controlled trial. Bmj. 2006;333(7566):465. https://doi. org/10.1136/bmj.38918.669317.4F.

17. Thiam DW, Yap SH, Chong SL. Clinical decision rules for Paediatric minor head injury: are CT scans a necessary evil? Ann Acad Med Singap. Sep 2015; 44(9):335-41.

18. Yıldızhan S, Boyacı MG, Özdinç Ş. How necessary is the computerized brain tomography in minor head trauma. Ulus Travma Acil Cerrahi Derg. 2019; 25(4):378-82. Minör kafa travmasında bilgisayarlı beyin tomografisi ne kadar gerekli? https://doi.org/10.5505/tites.2018.94849.

19. Vaniyapong T, Patumanond J, Ratanalert S, Limpastan K. Clinical indicators for traumatic intracranial findings in mild traumatic brain injury patients. Surg Neurol Int. 2019;10:64. https://doi.org/10.25259/sni-101-2019.

20. Borland ML, Dalziel SR, Phillips N, Dalton S, Lyttle MD, Bressan S, Oakley E, Hearps SJC, Kochar A, Furyk J, Cheek JA, Neutze J, Babl FE. Paediatric Research in Emergency Department International Collaborative group. Vomiting With Head Trauma and Risk of Traumatic Brain Injury. Pediatrics. 2018;141(4):e20173123. https://doi.org/10.1542/peds.2017-3123.

21. Dayan PS, Holmes JF, Atabaki S, et al. Association of Traumatic Brain Injuries With Vomiting in Children With Blunt Head Trauma. Ann Emerg Med. 2014; 63(6):657-65. https://doi.org/10.1016/j.annemergmed.2014.01.009.

22. Sharif-Alhoseini M, Khodadadi H, Chardoli M, Rahimi-Movaghar V. Indications for brain computed tomography scan after minor head injury. J Emerg Trauma Shock. 2011;4(4):472-6. https://doi.org/10.4103/0974-2700.86631.

23. Pandor A, Goodacre S, Harnan S, Holmes M, Pickering A, Fitzgerald P, et al. Diagnostic management strategies for adults and children with minor head injury: a systematic review and an economic evaluation. Health Technol Assess. 2011;15(27):1-202. https://doi.org/10.3310/hta15270.

24. Arambula SE, Reinl EL, El Demerdash N, McCarthy MM, Robertson CL. Sex differences in pediatric traumatic brain injury. Exp Neurol. 2019;317:168-79. https://doi.org/10.1016/j.expneurol.2019.02.016

\section{Publisher's Note}

Springer Nature remains neutral with regard to jurisdictional claims in published maps and institutional affiliations.

\section{Ready to submit your research? Choose BMC and benefit from}

- fast, convenient online submission

- thorough peer review by experienced researchers in your field

- rapid publication on acceptance

- support for research data, including large and complex data types

- gold Open Access which fosters wider collaboration and increased citations

- maximum visibility for your research: over $100 \mathrm{M}$ website views per year

At $\mathrm{BMC}$, research is always in progress.

Learn more biomedcentral.com/submissions 